\title{
Discontinued Drugs for the Treatment of Cardiovascular Disease from 2016 to 2018
}

\author{
Tingting Li ${ }^{1}$, Sida Jiang ${ }^{1}$, Bingwei $\mathrm{Ni}^{2}$, Qiuji Cui ${ }^{3}$, Qinan $\mathrm{Liu}^{3}$ and Hongping Zhao ${ }^{3, *}$ \\ 1 School of Pharmacy, China Pharmaceutical University, Nanjing 210009, Jiangsu, China \\ 2 School of Engineering, China Pharmaceutical University, Nanjing 210009, Jiangsu, China \\ 3 School of Science, China Pharmaceutical University, Nanjing 210009, Jiangsu, China \\ * Correspondence: zhaohongping@cpu.edu.cn; Tel.: +86-25-8327-1180
}

Received: 19 August 2019; Accepted: 3 September 2019; Published: 12 September 2019

\begin{abstract}
Cardiovascular drug research and development (R\&D) has been in active state and continuously attracts attention from the pharmaceutical industry. However, only one individual drug can eventually reach the market from about the 10,000 compounds tested. It would be useful to learn from these failures when developing better strategies for the future. Discontinued drugs were identified from a search performed by Thomson Reuters Integrity. Additional information was sought through PubMed, ClinicalTrials.gov, and pharmaceutical companies search. Twelve compounds discontinued for cardiovascular disease treatment after reaching Phase I-III clinical trials from 2016 to 2018 are detailed in this manuscript, and the reasons for these failures are reported. Of these, six candidates (MDCO-216, TRV027, ubenimex, sodium nitrite, losmapimod, and bococizumab) were dropped for lack of clinical efficacy, the other six for strategic or unspecified reasons. In total, three candidates were discontinued in Phase I trials, six in Phase II, and three in Phase III. It was reported that the success rate of drug R\&D utilizing selection biomarkers is higher. Four candidate developments (OPC-108459, ONO-4232, GSK-2798745, and TAK-536TCH) were run without biomarkers, which could be used as surrogate endpoints in the 12 cardiovascular drugs discontinued from 2016 to 2018. This review will be useful for those involved in the field of drug discovery and development, and for those interested in the treatment of cardiovascular disease.
\end{abstract}

Keywords: OPC-108459; ONO-4232; GSK-2798745; LIK-066; TAK-536TCH; bococizumab

\section{Introduction}

As the number 1 cause of death globally, cardiovascular diseases (CVDs) take the lives of 17.7 million people every year, about $31 \%$ of all deaths worldwide. CVDs are disorders of the heart and blood vessels, which include coronary heart disease, cerebrovascular disease, rheumatic heart disease, and other conditions [1]. Cardiovascular drug research and development (R\&D) has been in active state and continuously attracts attention from the pharmaceutical industry. However, only one individual drug that start preclinical or clinical development can eventually reach the market among the $\sim 10,000$ compounds tested.

Identifying a drug project that carries a high risk of imminent failure as early in the development as possible is critical for capital efficiency. Since the investment in clinical trials is just a portion of the full picture of drug development, the actual impact is usually considerably higher. Financial investment in failed projects is often factored in the cost of an average drug development. The cost of $R \& D$ of discontinued candidates reflects the price of the drugs that do reach the market. If a drug that is deemed to be discontinued, the earlier the discontinuation, the fewer the adverse events and the expenses for the process of drug development. Therefore, it would be helpful to recapitulate previous failures, report the reason for discontinuation, and give some meaningful advice. 
In the past years, the discontinued drugs for cardiovascular disease treatment are overall declining. There were 30 candidates in 2012, 11 candidates in 2013, and four candidates in 2014. The failures were due to efficacy, safety, strategic factors, and unknown reasons. In addition, the major reasons were efficacy and strategic factors [2-5]. Strategic re-evaluation focus has been one the major reasons for different drug developments' discontinuation over the years. While efficacy reasons are generally straightforward, reasons of termination due to strategy maybe complex [6]. Some discontinued drugs have been demonstrated to be effective and safe, but the changed internal and external environment of pharmaceutical companies and the competition in the market, or recruitment failure would lead pharmaceutical companies to terminate the development. Therefore, these drug candidates may possess development value in the future.

As the history of a failure can indicate a more promising way to a success, the aim of this review was to clarify the drug candidates for the treatment of cardiovascular disease discontinued after reaching clinical trials from 2016 to 2018, the phase of discontinuation, and the reason for it. There were 12 cardiovascular drugs discontinued in the last 3 years, according to the search results derived by setting milestone $=$ "Discontinued", milestone date $=$ from 20160101 to 20181231, and therapeutic group = "CARDIOVASCULAR DRUGS", and afterward filtering out some drugs that were not discontinued because of cardiovascular disease indications from Thomson Reuters Integrity, which stays at the cutting edge of drug R\&D and provides information integrated from multiple fields of drug R\&D, including every significant new drug under development from lead through early preclinical study and clinical phases, to launched or discontinued status and beyond [7]. Additional information was sought through PubMed, ClinicalTrials.gov, and pharmaceutical companies' search.

\section{Discontinued Drugs}

\subsection{General Overview}

According to Table 1, 12 drug candidates for the treatment of cardiovascular disease were removed from the CVD development pipeline from 2016 to 2018. Of these, three candidates were dropped in Phase I trials, six in Phase II, and three in Phase III. The detailed information of the 12 drugs is given below.

\subsection{Discontinued Drugs in Phase I}

\subsubsection{PF-06282999}

The thiouracil derivative PF-06282999 is a myeloperoxidase (MPO) inhibitor [8]. As an important member of the haem peroxidase-cyclooxygenase superfamily, MPO is a key factor in a great number of conditions within the group of cardiovascular diseases, neurodegenerative diseases, immune-mediated diseases, etc. [9]. Preclinical studies showed that PF-06282999 was rapidly and well absorbed in mice, rats, dogs, and monkeys with oral bioavailability values of $100 \%, 86 \%, 75 \%$, and $76 \%$, respectively. It was well distributed with steady state distribution volumes ranging from $0.5-2.1 \mathrm{~L} / \mathrm{kg}$ in the four species following intravenous administration (iv) [10]. PF-06282999 showed moderate permeability via both paracellular and transcellular pathways, and is a substrate for multidrug resistance protein 1 (MDR1) based on the bidirection transport study with a low efflux ration of 3.3. Renal clearance of unchanged PF-06282999 emerged as the principal clearance mechanism in humans other than hepatic clearance involving metabolizing enzymes and drug transporters [8]. Although PF-06282999 exhibited no relevant reversible and time- or NADPH-dependent inhibitory effects against human CYP450 enzymes in vitro, studies using human hepatocytes revealed moderate induction of CYP3A4 mRNA levels and midazolam-1'-hydroxylase activity in a PF-06282999 dose-dependent fashion, which is mediated by the pregnane $X$ receptor $[11,12]$. The Phase I trial study showed that the magnitude of the $4 \beta$-hydroxycholesterol or $6 \beta$-hydroxycortisol ratio change (endogenous biomarkers of CYP3A4) was generally smaller than the magnitude of an oral midazolam area under the curve (AUC) change with 
PF-06282999, so an oral midazolam drug-drug interaction (DDI) study is ultimately needed to gauge DDI via CYP3A4 induction, which is likely to be the case for weak to moderate CYP3A4 inducers or inducers that have a significant intestinal CYP3A4 induction component [13]. PF-06282999 was in Phase I clinical trials at Pfizer for the treatment of acute coronary syndrome [14]. However, product development for this indication was discontinued in the second quarter of 2017 with no reason.

\subsubsection{OPC-108459}

Otsuka Pharmaceutical Co., Ltd. was previously developing OPC-108459 for the treatment of paroxysmal and persistent atrial fibrillation. A Phase I trial study, which enrolled 48 patients with paroxysmal or persistent atrial fibrillation, was carried out to investigate the safety, pharmacokinetics (PK), and efficacy of OPC-108459 following 30-min continuous iv administration at 0.4, 0.8, 1.6, $2.4 \mathrm{mg} / \mathrm{kg}$, or placebo [15]. However, the development of the product was discontinued due to insufficient scientific evidence obtained in the Phase I clinical trials in 2016.

\subsubsection{ONO-4232}

As a prostanoid EP4 agonist, ONO-4232 improves left ventricular diastolic dysfunction and ameliorates acute and chronic heart failure in animal models [16]. It had been in Phase I clinical trials at Ono Pharmaceutical Co., Ltd. for the treatment of acute heart failure (AHF). The data showed that the plasma concentrations of ONO-4232 reached steady state approximately $2 \mathrm{~h}$ after the start of infusion and then declined rapidly after the end of infusion, and systemic exposure appeared to increase in a dose-proportional manner. Approximately $30 \%$ of the administered dose of ONO-4232 was excreted in the urine. ONO-4232 is generally well tolerated in the dose range of 0.001 to $0.27 \mathrm{ng} / \mathrm{kg} / \mathrm{min}$. This Phase I clinical study supported further evaluation of the cardiovascular effects of this first-in-class selective left ventricular lusitropic and venodilatory drug in patients with acutely decompensated heart failure [17]. However, Ono discontinued the development of ONO-4232 due to a strategic reason in January 2016 [18].

\subsection{Discontinued Drugs in Phase II}

\subsubsection{GSK-2798745}

As a transient receptor potential cation channel subfamily V member 4 (TRPV4) antagonist, GSK2798745 was developed as a novel therapeutic intervention for the treatment of pulmonary edema associated with heart failure (HF) [19]. It may improve pulmonary function, respiration, and gas exchange, as well as sleep-disordered breathing in patients with heart failure.

A Phase I trial was conducted for the PK of three $2.4 \mathrm{mg}$ tablet formulations of GSK2798745, which had been completed on December 2016 [20]. Single and repeat oral doses of GSK2798745 were given to healthy subjects and stable HF subjects to study the safety, tolerability, PK, and pharmacodynamics (PD) in a Phase II trial study [21]. A randomized, double-blind, sponsor-unblinded, placebo-controlled, Phase 2a crossover study in adults with heart failure had been completed by August 21, 2017, which was designed to investigate the effect of repeat administration of GSK2798745 on pulmonary gas exchange and pulmonary function [22]. However, GlaxoSmithKline (GSK) terminated the development of this product for unspecified reasons [23].

\subsubsection{MDCO-216}

MDCO-216, a recombinant apolipoprotein A-I (ApoA-I) Milano (AIM) and phospholipid complex, increases high-density lipoprotein (HDL)-cholesterol by mimicking HDL and its function, removing cholesterol and other lipids from tissues including the arterial wall and transporting them to the liver for elimination in reverse lipid transport [24].

In a preclinical study, MDCO-216 was administered to cynomolgus monkeys at 30, 100, and $300 \mathrm{mg} / \mathrm{kg}$ every other day for a total of 21 infusions, and effects on lipids, (apo) lipoproteins, 
and ex-vivo cholesterol efflux capacity were monitored. The change in lipid and lipoprotein profile sustained over a six-week period was well tolerated and did not lead to any obvious adverse effects [25]. Twenty-four healthy volunteers and 24 patients with documented coronary artery disease (CAD) received a $2 \mathrm{~h}$ infusion of MDCO-216 in a randomized, placebo controlled, single ascending dose from 5-40 mg Phase I trial study. The studies showed that MDCO-216 was well tolerated with no significant safety findings both in healthy and CAD patients and modified key lipid-related biomarkers [26-28]. A double-blind, placebo controlled Phase II clinical trial, which enrolled 126 patients with acute coronary syndrome (ACS) was carried out to measure the effect on atherosclerotic plaque burden and the impact on cholesterol efflux by intravascular ultrasound (IVUS). The patients received weekly $20 \mathrm{mg} / \mathrm{kg}$ MDCO-216 infusions over five weeks period [29]. Phase I and II trials from December 2015 to October 2016 showed that the agent did not ameliorate intracoronary atherosclerotic plaque enough for its further development, which led to a termination of its further study for atherosclerosis in November 2016 [30].

\subsubsection{TRV027}

As a first-in-class biased G protein-coupled receptor (GPCR) ligand that targets $\beta$-arrestin-biased angiotensin II type 1 receptor, TRV027 is a novel agent with vasodilating properties, which may improve both in-hospital and post-discharge clinical outcomes for patients with AHF [31].

In preclinical studies, TRV027 showed a dose-dependent decrease in mean arterial pressure and pulmonary capillary wedge pressure while preserving renal function (even in animals that were administered with furosemide). Apparent blood pressure (BP) effects of TRV027 were rapid in onset and relatively short in duration, providing an ideal hemodynamic profile for use in AHF [32-34]. A Phase I trial demonstrated that TRV027 was safe and well tolerated with a short-half-life (ranging between 2.4 and $13.2 \mathrm{~min}$ ) and dose-proportional increased in systemic exposure. Meanwhile, TRV027 could reduce $\mathrm{BP}$ to a greater degree in subjects with renin angiotensin system (RAS) activation than in those with normal plasma renin activity (PRA) levels [35]. Early clinical studies had been conducted by Trevena Inc. for the treatment of acute decompensated heart failure [36,37]. In May 2013, a license option agreement was signed by Trevena Inc. to Forest Laboratories for exclusive worldwide development following the completion of Phase IIb [38]. Biased Ligand of the Angiotensin Receptor Study in AHF (BLAST-AHF) was designed to determine the safety, efficacy, and optimal dose of TRV027 to advance into future studies. A multi-center, international, randomized, double-blind, placebo-controlled, parallel group, Phase IIlb dose-ranging study, enrolled 621 patients with AHF. TRV027 did not improve clinical status through 30-day follow-up compared with placebo [39,40]. In 2017, discontinuation of TRV027 was scheduled by Trevena for the treatment of acute decompensated HF.

\subsubsection{Ubenimex}

Ubenimex is an oral, small-molecule dual-inhibitor of aminopeptidase and leukotriene hydrolase, immunostimulant isolated from the fermentation broth of Streptomyces olivoreticuli by the Institute of Microbial Chemistry [41]. Nippon Kayaku Co., Ltd. firstly developed ubenimex as an adjunct to chemotherapy to extend survival and to maintain remission after treatment for acute non-lymphocytic leukemia in adults. Ubenimex was developed by Eiger BioPharmaceuticals for pulmonary arterial hypertension (PAH) as well as other inflammatory diseases involving leukotriene B4 (LTB4).

A preclinical study showed that ubenimex (bestatin), injected into the carotid artery, inhibited the activity of aminopeptidase and enkephalinase, producing an accumulation of enkephalins in the central nervous system. Enkephalins activate opioidergic receptors in the brain, but concomitantly produce a depression of the cholinergic-adrenergic interaction in the central nervous system, which is known to be a prerequisite for the hypertensive response to physostigmine in the rat [42]. In the SU5416/athymic rat model of severe pulmonary hypertension (PH), bestatin was highly effective in reversing PH in dose-dependent. Meanwhile, bestatin prevented PH-related death, opened the obstructed arterioles, and improved cardiac function. An inhalable formulation of bestatin also reversed 
established PH [43]. A randomized, double-blind, placebo-controlled Phase II trial (EIG-UBX-001, LIBERTY) in 61 pulmonary arterial hypertension patients in Canada and the US, to evaluate the efficacy, safety, and tolerability of ubenimex $150 \mathrm{mg}$ capsule three times a day, administered orally for 24 weeks, was completed [44]. Bestatin could inhibit HPAAF proliferation, migration, and differentiation by down-regulating p38 MAPK as well as Nox4 signaling pathways. In an autoimmune model of PH, inhibition of these pathways blocked perivascular inflammation, decreased Nox4 expression, reduced reactive oxygen species production, reversed arteriolar adventitial fibroblast activation, and attenuated PH development [45]. However, an open-label, single group Phase II trial (EIG-UBX-002, Liberty2) in Canada and the US, in 51 patients with PAH, to evaluate the long-term safety and efficacy of ubenimex po $150 \mathrm{mg}$, was terminated following the failure to demonstrate efficacy in EIG-UBX-001 [46].

\subsubsection{LIK-066}

LIK-066, an oral sodium-dependent glucose cotransporter (SGLT)-1 and -2 inhibitor, has been developed by Novartis for the treatment of obesity, non-alcoholic steatohepatitis, and type 2 diabetes. A multi-center, double-blind, parallel-group dose-finding Phase II study was carried out in 125 type 2 diabetes mellitus patients with HF to assess the efficacy, safety and tolerability of three doses of LIK066 compared to placebo or empagliflozin. However, the study was prematurely discontinued on May 4, 2018 due to slow enrollment that would preclude obtaining study results in a timely manner [47].

\subsubsection{Sodium Nitrite}

Savara Inc. developed a sodium nitrite inhalation solution as Aironite or AIR for treatment $\mathrm{PAH}$ and HF with preserved ejection fraction (HFpEF). In preclinical experiments of mice and rats with hypoxia or monocrotaline-induced $\mathrm{PAH}$, low doses of nebulized nitrite $(1.5 \mathrm{mg} / \mathrm{min})$ one or three times a week could minimally increase plasma and lung nitrite levels and prevent or reverse PAH and pathological right ventricular hypertrophy and failure. In vitro and in vivo studies revealed that xanthine oxidoreductase was responsible for hypoxic metabolism of nitric oxide in the lung. Furthermore, physiological levels of nitrite inhibited hypoxia-induced proliferation of cultured pulmonary artery smooth muscle cells via the nitric oxide-dependent induction of the cyclin-dependent kinase inhibitor p21Waf1/Cip1 [48]. Inhaled nitrite of newborn lambs with PH induced by hypoxia elicited a rapid and sustained reduction (approximately $65 \%$ ) in hypoxia-induced $\mathrm{PH}$, which was deoxyhemoglobin- and $\mathrm{pH}$-dependent, and associated with increased blood levels of iron-nitrosyl-hemoglobin [49].

The Phase I studies of inhaled nebulized sodium nitrite were carried out in a total of 82 healthy male and female subjects under normal and mildly hypoxic conditions, and following co-administration with steady-state sildenafil. Nebulized sodium nitrite was well tolerated following 6 days of every $8 \mathrm{~h}$ administration up to $90 \mathrm{mg}$, producing significant increases in circulating iron-nitrosyl hemoglobin, S-nitrosothiols, and the fraction exhaled nitric oxide. Pulmonary absorption of nitrite was rapid and complete, and the plasma exposure dose was proportional through the maximum tolerated dosage level of $90 \mathrm{mg}$, without accumulation following repeated inhalation. At higher dosage levels, dose-limiting toxicity were orthostasis (observed at $120 \mathrm{mg}$ ) and hypotension with tachycardia (at $176 \mathrm{mg}$ ), but venous methemoglobin did not exceed $3.0 \%$ at any time in any subject. Neither the tolerability nor PK of nitrite were impacted by conditions of mild hypoxia, or co-administration with sildenafil, supporting the safe use of inhaled nitrite in the clinical setting of PAH [50-52]. A single-center, pilot trial of low dose sodium nitrite ( 1 or $9.6 \mathrm{mg}$ dose) vs. placebo Phase I study was carried on the 11 hospitalized out-of-hospital cardiac arrest (OHCA) patients. Compared to placebo, infusion of low doses of sodium nitrite in comatose survivors of OHCA had no significant effects on heart rate within $30 \mathrm{~min}$ after infusion, systolic blood pressure, or methemoglobin levels. A $9.6 \mathrm{mg}$ sodium nitrite dose could produce significant $C_{15 \min }$ plasma nitrite elevations to $2-4 \mu \mathrm{M}[53,54]$.

A preliminary Phase II study of AIR001 for the treatment of PAH with 29 WHO Group 2 patients was finished to evaluate whether AIR-001 may be effective in reducing pulmonary vascular resistance 
(PVR), pulmonary capillary wedge pressure (PCWP), and right atrial pressure (RAP). The data demonstrated improvements in hemodynamic parameters and exercise capacity, and AIR001 was well tolerated [55]. An open-label, randomized, parallel-dose Phase II trial (AIR001-CS05) will be conducted to determine the safety and efficacy of nebulized sodium nitrate $80 \mathrm{mg}$ once-daily, $46 \mathrm{mg}$ or $80 \mathrm{mg}$ four times daily over 16 weeks in 29 subjects with WHO group 1 PAH by monitoring changes in PVR-from baseline/day 1 (start of study drug) to the end of the study. However, it has been terminated due to acquisition of sponsor and change in corporate priorities [56]. Another Phase II trial (AIR001-CS06) to evaluate the intermediate/long-term safety and efficacy of nebulized AIR-001 who have completed the 16 week AIR001-CS05 trial in 17 patients has been terminated due to the same reason [57]. In a double-blind, randomized, placebo-controlled, parallel-group Phase II trial, 26 subjects with HFpEF underwent cardiac catheterization with simultaneous expired gas analysis at rest and during exercise, prior to and following treatment with inhaled sodium nitrite (90 mg) or placebo. Inhaled nitrite reduced resting PCWP, improved pulmonary artery compliance and decreased mean pulmonary artery pressures at rest and with exercise. Nitrite reduced RAP with no effect on cardiac output or stroke volume. Acute administration of inhaled sodium nitrite reduces biventricular filling pressures and pulmonary artery pressures at rest and during exercise in HFpEF $[58,59]$. To determine the effect of chronic administration of inhaled sodium nitrite on exercise capacity in HFpEF, a placebo-controlled, 2-treatment, crossover trial of 105 patients with HFpEF was designed. There were no significant between-treatment phase differences in daily activity levels, Kansas City Cardiomyopathy Questionnaire Clinical Summary Score, functional class, echocardiographic E/e' ratio, or N-terminal fragment of the prohormone brain natriuretic peptide levels. These results showed that administration of inhaled inorganic nitrite for 4 weeks did not result in significant improvement in exercise capacity $[60,61]$. Savara Inc. discontinued the development of sodium nitrite for the negative outcome from inorganic nitrite delivery to Improve Exercise Capacity (INDIE) study in HFpEF [62].

\subsection{Discontinued Drugs in Phase III}

\subsubsection{TAK-536TCH}

TAK-536TCH is a fixed-dose combination of azilsartan (AZI), amlodipine (AML) and hydrochlorothiazide (HCTZ) developed by Takeda Pharmaceutical Co., Ltd. for the treatment of essential hypertension [63]. A randomized, crossover Phase I trial study to evaluate the food-effect on the PK and safety of a single oral dose of TAK-536TCH tablet under fasted and fed conditions in the morning in 12 healthy adult male subjects was completed in 2016 [64]. Finished in 2013, a Phase II/III trial study, which enrolled 353 patients with grade I or II essential hypertension by 10-week treatment of TAK-536TCH, showed that TAK-536TCH (AZI/AML/HCTZ 20/5/12.5 mg) led to a significantly greater reduction in BP than the dual therapy (TAK-536CCB, AZI/AML), and was well tolerated in Japanese patients [65,66]. Since 2014, Phase III, open-label, multicenter clinical study was carried out on 341 patients with essential hypertension, which comprised a 4-week run-in period and 52-week treatment period. The primary and secondary endpoints were long-term safety and BP (office and home), respectively. Triple combination therapy with a single tablet of $20 \mathrm{mg}$ AZL, $5 \mathrm{mg}$ AML, and $12.5 \mathrm{mg}$ HCTZ was well tolerated, and provided consistent BP-lowering effects for patients with essential hypertension whose BP was not adequately controlled by dual combination therapy with $20 \mathrm{mg}$ AZL and $5 \mathrm{mg}$ AML $[67,68]$. However, its preregistration for essential hypertension was canceled due to insufficient new value provided in the Japanese market in May 2017 [63].

\subsubsection{Losmapimod}

Developed by GSK, losmapimod is an inhibitor of p38 mitogen-activated protein kinases (MAPKs) $\alpha$ and $\beta$ isoforms. P38 MAPKs determine the transcription and translation of inflammatory mediators like tumor necrosis factor alpha (TNF- $\alpha$ ) and interleukins 1 (IL-1), which are activated in atherosclerotic 
disease [69]. Furthermore, they undermine NO bioavailability by influencing the formation of reactive oxygen species resulting in vasoconstriction and endothelial dysfunction.

In preclinical studies, losmapimod could significantly and dose-dependently improve survival and endothelial function, and attenuated hypertension, cardiac remodeling and interleukin-1 $\beta$ (IL-1 $\beta$ ) in the spontaneously hypertensive stroke-prone rat (SHR-SP) [70]. Losmapimod progressively suppressed dynamin-like protein 1(DLP1)/mitochondrial fission factor (MFF) from $6 \mathrm{~h}$ to $24 \mathrm{~h}$ after ischemia-reperfusion injury of rats, which suggested potential neuroprotective effect via suppressing mitochondrial fragmentation/mitophagy in stroke [71].

A single-center, single blind, Phase I and two-part study characterized the safety, tolerability, PK and PD of losmapimod and its metabolite GSK198602 in healthy Japanese volunteers. Losmapimod was found safe and well-tolerated following single doses $(2.5 \mathrm{mg}, 7.5 \mathrm{mg}, 20 \mathrm{mg})$ and repeat doses (7.5 mg for 14 days) of oral administration in healthy Japanese volunteers, and no serious adverse events occurred during the study. The Tmax of losmapimod was $3-4 \mathrm{~h}$, and the mean terminal elimination half-lives (T1/2) was approximately 7.9-9.0 h [72,73]. Another Phase I clinical study completed in 2010 showed that single iv infusion of losmapimod in healthy volunteers was safe and well tolerated, and may potentially serve as an initial loading dose in ACS as rapid exposure. A direct-link maximal inhibitory effect model related plasma concentrations to $\mathrm{pHSP} 27$ concentrations $[74,75]$. The population PK/PD meta-analysis of Phase I clinical studies in healthy volunteers indicated that losmapimod plasma concentration had no significant effect on QT-interval prolongation [76]. A total of 535 non-ST-segment elevation myocardial infarction (NSTEMI) patients were enrolled to receive oral losmapimod or matching placebo for 12 weeks in Phase II trial study (SOLSTICE trial, study of losmapimod treatment on inflammation and infarct size), which was confirmed the safety and efficacy of losmapimod in NSTEMI patients. Losmapimod was well tolerated in NSTEMI patients according to adverse events, alanine aminotransferase (ALT) concentrations, and cardiac events, and might improve outcomes after ASCs (MRI recruitment target, infarct size, left ventricular ejection fraction, left ventricular remodeling). Meanwhile, high-sensitivity C-reactive protein (hsCRP), B-type natriuretic peptide (BNP), and IL-6 were lower in losmapimod arma than placebo $[77,78]$. Based on the promising preliminary data of the Phase II SOLSTICE study, 3503 patients hospitalized with NSTEMI or STEMI were further enrolled in the Phase III (LATITUDE-TIMI 60) study to evaluate its effects in patients with ACS, which was completed in December, 2015. The primary endpoint (cardiovascular death, MI or severe recurrent ischemia requiring urgent coronary artery revascularization) occurred by 12 weeks in 123 patients treated with placebo $(7.0 \%)$ and 139 patients treated with losmapimod $(8.1 \%)$. The on-treatment rates of serious adverse events were $16.0 \%$ with losmapimod and $14.2 \%$ with placebo [79-81]. According to the unmet primary endpoint of its efficiency in Phase A of the trial and inadequate support to investment in the part B of the study, the further investigation of losmapimod for ACS was discontinued in January 2016 [82].

\subsubsection{Bococizumab}

As a proprotein convertase subtilisin-kexin type 9 (PCSK9) inhibitor, bococizumab lowers low-density lipoprotein (LDL) level. PCSK9 is a serine protease, which bonding to LDL receptor (LDL-R) results in the aggregation of LDL cholesterol (LDL-C), an important factor causing atherosclerotic heart disease. Working as a humanized monoclonal antibody $(\mathrm{mAb})$, bococizumab extracellularly influences circulating PCSK9 either by secluding it or blocking the bonding [83,84].

In Phase I studies, treatment with bococizumab by single or multiple IV or SC doses could lead to significant low-density lipoprotein cholesterol (LDL-C) reductions compared with placebo (43-84\%) [85-88]. Bococizumab was generally safe and well tolerated in the short duration studies, both in diet-managed hypercholesterolemic subjects and in those on concomitant atorvastatin therapy, which was in line with results of the Phase II studies [89]. Peak plasma concentrations (Cmax) and T1/2 of bococizumab increased in a dose-dependent manner. The relative bioavailability for the $200 \mathrm{mg}$ SC dosages ranged 22-26\%. Multiple-dose study indicated that dose-related accumulation was minimal 
by weekly IV infusions of bococizumab, which geometric mean observed accumulation ratios (Rac) were $1.3,1.7,1.8$, and 2.0 for the $0.25,0.5,1$, and $1.5 \mathrm{mg} / \mathrm{kg}$ groups, respectively. A mechanism-based drug-target binding model using bococizumab Phase I and IIA trial data was developed to account for bococizumab, PCSK9, and LDL-C concentrations, and the effects of co-administration of statins. The model indicated that statins could predict an increase in LDL-C clearance of bococizumab by co-administration, which was consistent with the proposed effect of statins in stimulating both LDLR and PCSK9 production and the target-mediated disposition of bococizumab [83,90]. In July 2016, a Phase I trial for hypercholesterolemia in combination with recombinant human hyaluronidase (rHuPH20) was terminated due to business priorities regarding study execution [91,92].

The six SPIRE (studies of PCSK9 inhibition and the reduction of vascular events) lipid-lowering trials of Phase III enrolled 4300 patients with hyperlipidemia. Bococizumab showed wide variation in the LDL-C, which was present as early as 12 weeks (largely before the detection of antidrug antibodies) and also at 52 weeks among patients who did not have an antidrug-antibodies response [93-95]. Another two SPIRE trials of Phase III (multi center, double blind, randomized, placebo controlled, parallel group) study involved 27,438 patients with high cardiovascular risk to evaluate the efficacy, safety, and tolerability of bococizumab, in reducing the occurrence of major cardiovascular events. Compared to placebo, bococizumab had no benefit with respect to the primary end point of major adverse cardiovascular events in SPIRE-1 trial involving lower-risk patients. In contrast, a significant benefit in the SPIRE-2 trial involving higher-risk patients was shown [96,97]. Based in part on the high rate of immunogenicity of the drug, as well as on the wide variation in the LDL-C response among the patients, Pfizer discontinued global development of bococizumab because the totality of clinical information indicated almost no possibility for bococizumab to provide value to patients, physicians and shareholders. 
Table 1. Discontinued drugs for the treatment of cardiovascular disease from 2016 to 2018.

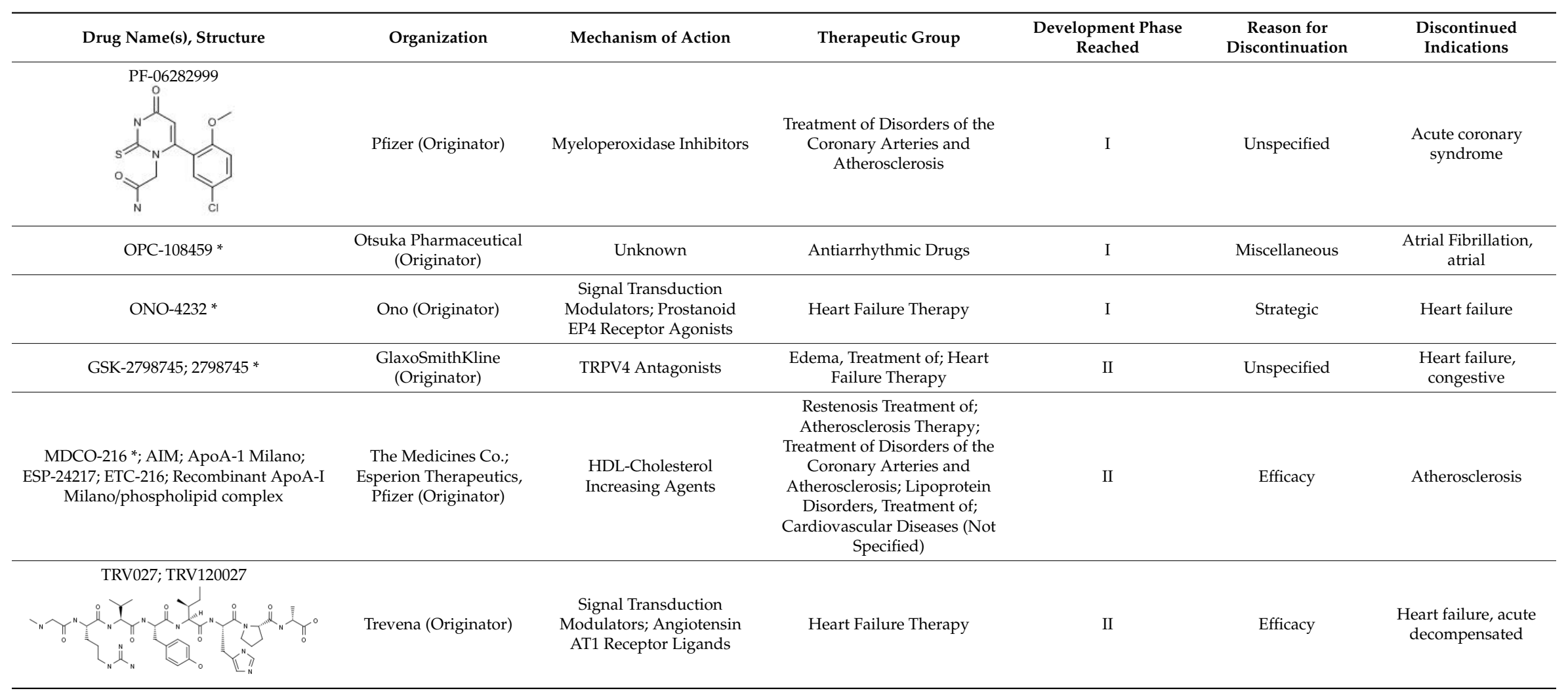


Table 1. Cont.

\begin{tabular}{|c|c|c|c|c|c|c|}
\hline Drug Name(s), Structure & Organization & Mechanism of Action & Therapeutic Group & $\begin{array}{c}\text { Development Phase } \\
\text { Reached }\end{array}$ & $\begin{array}{c}\text { Reason for } \\
\text { Discontinuation }\end{array}$ & $\begin{array}{l}\text { Discontinued } \\
\text { Indications }\end{array}$ \\
\hline & Nippon Kayaku & $\begin{array}{c}\text { Immunostimulant; } \\
\text { Peptidase inhibitor; } \\
\text { Leucotriene B4 antagonist; } \\
\text { Hit substrate-selective } \\
\text { leucotriene A4 hydrolase } \\
\text { inhibitor }\end{array}$ & $\begin{array}{c}\text { Lung Cancer Therapy; } \\
\text { Leukemia Therapy; } \\
\text { Immunostimulants; } \\
\text { Cardiovascular Diseases (Not } \\
\text { Specified); } \\
\text { Pulmonary Hypertension, } \\
\text { Treatment of } \\
\end{array}$ & II & Efficacy & $\begin{array}{l}\text { Hypertension, } \\
\text { pulmonary arterial }\end{array}$ \\
\hline-0 & Novartis & $\begin{array}{l}\text { SGLT-1 Inhibitors; SGLT-2 } \\
\text { Inhibitors }\end{array}$ & $\begin{array}{l}\text { Treatment of Female Sexual } \\
\text { Dysfunction; Antiobesity Drugs; } \\
\text { Metabolic Disorders (Not } \\
\text { Specified); Heart Failure } \\
\text { Therapy; Type } 2 \text { Diabetes, } \\
\text { Agents for }\end{array}$ & II & $\begin{array}{l}\text { Strategic (slow } \\
\text { enrollment) }\end{array}$ & Heart failure \\
\hline $\begin{array}{l}\text { Sodium nitrite; AIR-001; S-2252; TV-1001; } \\
\qquad \stackrel{\mathrm{TV}-1001-\mathrm{SR}}{=}-\mathrm{OH}\end{array}$ & TheraVasc & Nitric oxide stimulant & $\begin{array}{l}\text { Septic Shock, Hemorrhagic } \\
\text { Stroke, Non-Opioid Analgesics, } \\
\text { Neuropathic Pain, Poisoning, } \\
\text { Acute Myocardial Infarction, } \\
\text { Cerebrovascular Diseases, } \\
\text { Ischemia, Peripheral Arterial } \\
\text { Disease; Pulmonary } \\
\text { Hypertension, Treatment of; } \\
\text { Ulcers of the Extremities, } \\
\text { Scleroderma Agents for; } \\
\text { Cardioprotective Agents; } \\
\text { Heart Failure Therapy; } \\
\text { Antibacterial Drugs }\end{array}$ & II & Efficacy & Heart failure \\
\hline $\begin{array}{l}\text { TAK-536TCH \#; } \\
\text { Azilsartan/amlodipine/hydrochlorothiazide; } \\
\text { TAK-536/amlodipine/hydrochlorothiazide }\end{array}$ & Takeda (Originator) & $\begin{array}{l}\text { Signal Transduction } \\
\text { Modulators; Insulin } \\
\text { Sensitizers; Calcium } \\
\text { Channel Blockers; } \\
\text { Angiotensin AT2 Receptor } \\
\text { Antagonists; Angiotensin } \\
\text { AT1 Receptor Antagonists }\end{array}$ & Hypertension, Treatment of & III & Strategic & $\begin{array}{l}\text { Hypertension, } \\
\text { essential }\end{array}$ \\
\hline $\begin{array}{c}\text { Bococizumab *; L1L3; PF-04950615; } \\
\text { RN-316 }\end{array}$ & Pfizer (Originator) & $\begin{array}{l}\text { Anti-PCSK9 (Proprotein } \\
\text { Convertase } \\
\text { Subtilisin/Kexin-Type 9) }\end{array}$ & $\begin{array}{l}\text { Atherosclerosis Therapy; } \\
\text { Disorders of the Coronary } \\
\text { Arteries and Atherosclerosis; } \\
\text { Lipoprotein Disorders, } \\
\text { Treatment of }\end{array}$ & III & Efficacy & $\begin{array}{c}\text { Hyperlipidemia, } \\
\text { Hypercholesterolemia, } \\
\text { familial }\end{array}$ \\
\hline
\end{tabular}


Table 1. Cont.

\begin{tabular}{|c|c|c|c|c|c|c|}
\hline Drug Name(s), Structure & Organization & Mechanism of Action & Therapeutic Group & $\begin{array}{c}\text { Development Phase } \\
\text { Reached }\end{array}$ & $\begin{array}{c}\text { Reason for } \\
\text { Discontinuation }\end{array}$ & $\begin{array}{c}\text { Discontinued } \\
\text { Indications }\end{array}$ \\
\hline $\begin{array}{l}\text { Losmapimod; 856553; GSK-AHAB; } \\
\text { GW-856553; GW-856553X; SB-856553 }\end{array}$ & $\begin{array}{l}\text { GlaxoSmithKline } \\
\text { (Originator) }\end{array}$ & $\begin{array}{c}\text { Mitogen-Activated Protein } \\
\text { Kinase 14(MAPK14; MAPK } \\
\text { p38 alpha) Inhibitors; } \\
\text { Signal Transduction } \\
\text { Modulators }\end{array}$ & $\begin{array}{l}\text { Chronic Obstructive Pulmonary } \\
\text { Diseases (COPD), Treatment of; } \\
\text { Treatment of Renal Diseases; } \\
\text { Neuropathic Pain, Treatment of; } \\
\text { Atherosclerosis Therapy; } \\
\text { Treatment of Disorders of the } \\
\text { Coronary Arteries and } \\
\text { Atherosclerosis; Antidepressants; } \\
\text { Rheumatoid Arthritis; } \\
\text { Lipoprotein Disorders, } \\
\text { Treatment of; Antipsoriatics }\end{array}$ & III & Efficacy & $\begin{array}{l}\text { Acute coronary } \\
\text { syndrome }\end{array}$ \\
\hline
\end{tabular}

* Structures of the drugs are unavailable; \# Fixed-dose combination of different drugs. 


\section{Expert Opinion}

These 12 drugs discontinued from 2016 to 2018 together with the 17 drugs discontinued in 2013-2015 were the cardiovascular drugs dropped from the global cardiovascular drug development pipeline in the past 6 years $[4,5]$. Each year less than five cardiovascular drugs were discontinued after reaching Phase I-III clinical trials, which was significantly fewer than the 30 discontinuations reported in 2012 [3] and 19 discontinuations in 2011 [2]. The trend of increasing numbers of cardiovascular drug development terminations in recent years has changed.

Of the 12 drugs failed from 2016 to 2018, the most eye-catching three drugs are ONO-4232, LIK-066, and bococizumab, which are both new chemical entities (NCE) without patent protection. Ono Pharmaceutical Co., Ltd. discontinued the developments of ONO-4232 for strategic reasons. LIK-066 was prematurely discontinued by Novartis due to slow enrollment, which would preclude obtaining study results in a timely manner. Developments of these three candidates still deserve further concerns. In addition to alirocumab and evolocumab for cholesterol-lowering and evolocumab for the prevention of heart attack and stroke, which are the only two approved inhibitors of PCSK9, bococizumab is another monoclonal antibody against PCSK9 $[98,99]$. As its mode of action differs from that of statins, anti-PCSK9 may provide benefit to people who do not achieve desirable LDL-C levels with statins or cannot tolerate them.

Among the failed cardiovascular drugs from 2016 to 2018, six drugs were dropped for lack of clinical efficacy, demonstrating the need for the development of more predictive animal models, and the need to develop experimental medicine paradigms that are more predictive of outcomes and to carry out such proof-of-concept clinical trials much earlier in development, especially during first-in-man studies [100]. With the development of artificial intelligence (AI) assistant drug designing, the problem for poor efficacy or safety may be solved by deep learning technology to predict and optimize the properties of the candidates.

It was reported that the success rate of drug R\&D utilizing selection biomarkers is higher [101]. There are four candidate developments (OPC-108459, ONO-4232, GSK-2798745, TAK-536TCH) run without biomarkers, which could be used as surrogate endpoints in the 12 cardiovascular drugs discontinued from 2016 to 2018. In order to reduce the attrition rate of cardiovascular drug R\&D, trials run with biomarker-selected patients should be given priority to study.

Overall, the range of the discontinued compounds discussed offers a relevant picture of what is currently in the pipeline for the CVD conditions such as those mentioned in this retrospective review. Future research may benefit from these developments and investigators conducting similar studies may learn from these failures.

Funding: This work was supported by grants from the Fundamental Research Funds for the Central Universities (No. 2632018YX03, 2632019ZD05) and the National Natural Science Foundation of China (No.81503150).

Conflicts of Interest: The authors declare no conflict of interest.

\section{References}

1. WHO. Cardiovascular Diseases. 2017. Available online: http://www.who.int/cardiovascular_diseases/en/ (accessed on 28 December 2018).

2. Zhao, H.P.; Jiang, H.M.; Xiang, B.R. Discontinued drugs in 2011: Cardiovascular drugs. Expert Opin. Investig. Drugs 2012, 21, 1449-1462. [CrossRef] [PubMed]

3. Zhao, H.P.; Jiang, H.M.; Xiang, B.R. Discontinued drugs in 2012: Cardiovascular drugs. Expert Opin. Investig. Drugs 2013, 22, 1437-1451. [CrossRef] [PubMed]

4. Zhao, H.P.; Xiang, B.R. Discontinued cardiovascular drugs in 2013 and 2014. Expert Opin. Investig. Drugs 2015, 24, 1083-1092. [CrossRef] [PubMed]

5. Zhao, H.P.; Dai, Y.; Xiang, B.R. Discontinued cardiovascular drugs in 2015. Expert Opin. Investig. Drugs 2016, 25, 1039-1101. [CrossRef] [PubMed] 
6. Lièvre, M.; Ménard, J.; Bruckert, E.; Cogneau, J.; Delahaye, F.; Giral, P.; Leitersdorf, E.; Luc, G.; Masana, L.; Moulin, P.; et al. Premature discontinuation of clinical trial for reasons not related to efficacy, safety, or feasibility. BMJ 2001, 322, 603-605. [CrossRef]

7. Integrity: Essential Knowledge to Empower Your Drug Discovery and Development. Available online: https://clarivate.com/wp-content/uploads/2018/03/Crv_LS_Integrity_SellSheetShort_A4_FA.pdf (accessed on 28 June 2019).

8. Dong, J.Q.; Varma, M.V.; Wolford, A.; Ryder, T.; Di, L.; Feng, B.; Terra, S.G.; Sagawa, K.; Kalgutkar, A.S. Pharmacokinetics and Disposition of the Thiouracil Derivative PF-06282999, an Orally Bioavailable, Irreversible Inactivator of Myeloperoxidase Enzyme, Across Animals and Humans. Drug Metab. Dispos. 2016, 44, 209-219. [CrossRef]

9. Lazarevic-Pasti, T.; Leskovac, A.; Vasic, V. Myeloperoxidase Inhibitors as Potential Drugs. Curr. Drug Metab. 2015, 16, 168-190. [CrossRef]

10. Ruggeri, R.B.; Buckbinder, L.; Bagley, S.W.; Carpino, P.A.; Conn, E.L.; Dowling, M.S.; Fernando, D.P.; Jiao, W.; Kung, D.W.; Orr, S.T; et al. Discovery of 2-(6-(5-Chloro-2-methoxyphenyl)-4-oxo-2-thioxo-3,4dihydropyrimidin-1(2H)-yl)acetamide (PF-06282999): A Highly Selective Mechanism-Based Myeloperoxidase Inhibitor for the Treatment of Cardiovascular Diseases. J. Med. Chem. 2015, 58, 8513-8528. [CrossRef]

11. Dong, J.Q.; Gosset, J.R.; Fahmi, O.A.; Lin, Z.; Chabot, J.R.; Terra, S.G.; Le, V.; Chidsey, K.; Nouri, P.; Kim, A.; et al. Examination of the Human Cytochrome P4503A4 Induction Potential of PF-06282999, an Irreversible Myeloperoxidase Inactivator: Integration of Preclinical, In Silico, and Biomarker Methodologies in the Prediction of the Clinical Outcome. Drug Metab. Dispos. 2017, 45, 501-511. [CrossRef]

12. Moscovitz, J.E.; Lin, Z.; Johnson, N.; Tu, M.; Goosen, T.C.; Weng, Y.; Kalgutkar, A.S. Induction of human cytochrome P450 3A4 by the irreversible myeloperoxidase inactivator PF-06282999 is mediated by the pregnane $X$ receptor. Xenobiotica 2018, 48, 647-655. [CrossRef]

13. ClinicalTrials. A Study to Test the Safety, Amount and Effects of PF-06282999 in Healthy Overweight Adults and a Study to Test the Effects of PF-06282999 on the Amount of the Approved Drug, Midazolam, in Healthy Adults. Available online: https://www.clinicaltrials.gov/ct2/show/record/NCT01707082?term=PF-06282999\& rank=2\&view=record (accessed on 10 April 2019).

14. Roth Flach, R.J.; Su, C.; Bollinger, E.; Cortes, C.; Robertson, A.W.; Opsahl, A.C.; Coskran, T.M.; Maresca, K.P.; Keliher, E.J.; Yates, P.D.; et al. Myeloperoxidase inhibition in mice alters atherosclerotic lesion composition. PLoS ONE 2019, 14, e0214150. [CrossRef] [PubMed]

15. ClinicalTrials. A Trial to Determine the Safety, Pharmacokinetics, and Efficacy of OPC-108459 Administered as a Single Intravenous Dose to Patients With Paroxysmal or Persistent Atrial Fibrillation (AF). Available online: https:/www.clinicaltrials.gov/ct2/show/record/NCT02069119?term=OPC-108459\&rank=1 (accessed on 10 April 2019).

16. Kanaji, T.; Fuchibe, K.; Takahashi, M.; Shiroya, T. ONO-4232, an EP4-selective Agonist, Improves Left Ventricular Diastolic Dysfunction and Ameliorates Acute and Chronic Heart Failure in Animal Models. Circulation 2012, 126, A15345.

17. Ward, C.L.; Jamieson, V.; Nabata, T.; Sharpe, J.; Dozono, K.; Suto, F.; Hashimoto, Y.; Gussak, I. First Clinical Experience with ONO-4232: A Randomized, Double-blind, Placebo-controlled Healthy Volunteer Study of a Novel Lusitropic Agent for Acutely Decompensated Heart Failure. Clin. Ther. 2016, 38, 1109-1121. [CrossRef] [PubMed]

18. ONO. Consolidated Financial Statements (Marc 2016). 11 May 2017. Available online: http://www.ono.co.jp/ jpnw/ir/pdf/k_tanshin/2934r/03.pdf (accessed on 29 October 2018).

19. Goyal, N.; Skrdla, P.; Schroyer, R.; Kumar, S.; Fernando, D.; Oughton, A.; Norton, N.; Sprecher, D.L.; Cheriyan, J. Clinical Pharmacokinetics, Safety, and Tolerability of a Novel, First-in-Class TRPV4 Ion Channel inhibitor, GSK27987445, in Healthy and Heart Failure Subjects. Am. J. Cardiovasc. Drugs 2019, 19, 335-342. [CrossRef] [PubMed]

20. ClinicalTrials. A Phase I Study to Assess the Pharmacokinetics of GSK2798745 Tablets. Available online: https://www.clinicaltrials.gov/ct2/show/record/NCT02925546 (accessed on 21 April 2018).

21. ClinicalTrials. A First Time in Human Study to Evaluate the Safety, Tolerability, Pharmacokinetics, and Pharmacodynamics of GSK2798745 in Healthy Subjects and Stable Heart Failure Patients. Available online: https://www.clinicaltrials.gov/ct2/show/record/NCT02925546 (accessed on 21 November 2017). 
22. ClinicalTrials. A Study to Evaluate the Effect of the Transient Receptor Potential Vanilloid 4 (TRPV4) Channel Blocker, GSK2798745, on Pulmonary Gas Transfer and Respiration in Patients With Congestive Heart Failure. Available online: https:/clinicaltrials.gov/ct2/show/NCT02497937 (accessed on 21 November 2017).

23. GSK. 2018 Full Year Results. Available online: https://www.gsk.com/media/5293/fy-2018-results-slides.pdf (accessed on 28 August 2019).

24. Caparon, M.H.; Rust, K.J.; Hunter, A.K.; McLaughlin, J.K.; Thomas, K.E.; Herberg, J.T.; Shell, R.E.; Lanter, P.B.; Bishop, B.F.; Dufield, R.L.; et al. Integrated solution to purification challenges in the manufacture of a soluble recombinant protein in E. coli. Biotechnol. Bioeng. 2010, 105, 239-249. [CrossRef] [PubMed]

25. Kempen, H.J.; Gomaraschi, M.; Bellibas, S.E.; Plassmann, S.; Zerler, B.; Collins, H.L.; Adelman, S.J.; Calabresi, L.; Wijngaard, P.L. Effect of repeated apoA-IMilano/POPC infusion on lipids, (apo)lipoproteins, and serum cholesterol efflux capacity in cynomolgus monkeys. J. Lipid. Res. 2013, 54, 2341-2353. [CrossRef] [PubMed]

26. Kempen, H.J.; Asztalos, B.F.; Moerland, M.; Jeyarajah, E.; Otvos, J.; Kallend, D.G.; Bellibas, S.E.; Wijngaard, P.L. High-Density Lipoprotein Subfractions and Cholesterol Efflux Capacities After Infusion of MDCO-216 (Apolipoprotein A-IMilano/Palmitoyl-Oleoyl-Phosphatidylcholine) in Healthy Volunteers and Stable Coronary Artery Disease Patients. Arterioscler. Thromb. Vasc. Biol. 2016, 36, 736-742. [CrossRef] [PubMed]

27. Kallend, D.G.; Reijers, J.A.; Bellibas, S.E.; Bobillier, A.; Kempen, H.; Burggraaf, J.; Moerland, M.; Wijngaard, P.L. A single infusion of MDCO-216 (ApoA-1 Milano/POPC) increases ABCA1-mediated cholesterol efflux and pre-beta $1 \mathrm{HDL}$ in healthy volunteers and patients with stable coronary artery disease. Eur. Heart J. Cardiovas. Pharmacother. 2016, 2, 23-29. [CrossRef]

28. Kempen, H.J.; Gomaraschi, M.; Simonelli, S.; Calabresi, L.; Moerland, M.; Otvos, J.; Jeyarajah, E.; Kallend, D.; Wijngaard, P.L.J. Persistent changes in lipoprotein lipids after a single infusion of ascending doses of MDCO-216 (apoA-IMilano/POPC) in healthy volunteers and stable coronary artery disease patients. Atherosclerosis 2016, 255, 17-24. [CrossRef]

29. ClinicalTrials. MDCO-216 Infusions Leading to Changes in Atherosclerosis: A Novel Therapy in Development to Improve Cardiovascular Outcomes-Proof of Concept Intravascular Ultrasound (IVUS), Lipids, and Other Surrogate Biomarkers Trial (PILOT). Available online: https://www.clinicaltrials.gov/ct2/show/record/ NCT02678923?term=MDCO-216\&rank=1 (accessed on 12 April 2019).

30. The Medicines Company. The Medicines Company Discontinues Development of MDCO-216, its Investigational Cholesterol Efflux Promoter. Available online: http://www.themedicinescompany.com/ investors/news/medicines-company-discontinues-development-mdco-216-its-investigational-cholesterol (accessed on 3 April 2018).

31. Singh, A.; Laribi, S.; Teerlink, J.R.; Mebazaa, A. Agents with vasodilator properties in acute heart failure. Eur. Heart J. 2017, 38, 317-325. [CrossRef]

32. Violin, J.D.; DeWire, S.M.; Yamashita, D.; Rominger, D.H.; Nguyen, L.; Schiller, K.; Whalen, E.J.; Gowen, M.; Lark, M.W. Selectively engaging beta-arrestins at the angiotensin II type 1 receptor reduces blood pressure and increases cardiac performance. J. Pharmacol. Exp. Ther. 2010, 335, 572-579. [CrossRef]

33. Boerrigter, G.; Lark, M.W.; Whalen, E.J.; Soergel, D.G.; Violin, J.D.; Burnett, J.C., Jr. Cardiorenal actions of TRV120027, a novel ss-arrestin-biased ligand at the angiotensin II type I receptor, in healthy and heart failure canines: A novel therapeutic strategy for acute heart failure. Circ. Heart Fail. 2011, 4, 770-778. [CrossRef]

34. Boerrigter, G.; Soergel, D.G.; Violin, J.D.; Lark, M.W.; Burnett, J.C., Jr. TRV120027, a novel beta-arrestin biased ligand at the angiotensin II type I receptor, unloads the heart and maintains renal function when added to furosemide in experimental heart failure. Circ. Heart Fail. 2012, 5, 627-634. [CrossRef]

35. Soergel, D.G.; Subach, R.A.; Cowan, C.L.; Violin, J.D.; Lark, M.W. First clinical experience with TRV027: Pharmacokinetics and pharmacodynamics in healthy volunteers. J. Clin. Pharmacol. 2013, 53, 892-899. [CrossRef]

36. Soergel, D.G.; Subach, R.A.; James, I.E.; Conrad, L.C.; Maxine, G.; Michael, L. TRV027, a $\beta$-arrestin biased ligand at the angiotensin 2 type 1 receptor, produces rapid, reversible changes in hemodynamics in patients with stable systolic heart failure. Am. Coll. Cardiol. 2013, 61, 1221-1284. [CrossRef]

37. ClinicalTrials. A Study to Explore the Efficacy of TRV027 in Patients Hospitalized for Acute Decompensated Heart Failure (BLAST-AHF). Available online: https:/www.clinicaltrials.gov/ct2/show/study/NCT01966601? term $=$ NCT01966601\&rank=1 (accessed on 10 November 2018). 
38. Trevena. TRV027. Available online: http://www.trevena.com/TRV027.php (accessed on 10 November 2018).

39. Felker, G.M.; Butler, J.; Collins, S.P.; Cotter, G.; Davison, B.A.; Ezekowitz, J.A.; Filippatos, G.; Levy, P.D.; Metra, M.; Ponikowski, P.; et al. Heart failure therapeutics on the basis of a biased ligand of the angiotensin-2 type 1 receptor. Rationale and design of the BLAST-AHF study (Biased Ligand of the Angiotensin Receptor Study in Acute Heart Failure). JACC Heart Fail. 2015, 3, 193-201. [CrossRef]

40. Pang, P.S.; Butler, J.; Collins, S.P.; Cotter, G.; Davison, B.A.; Ezekowitz, J.A.; Filippatos, G.; Levy, P.D.; Metra, M.; Ponikowski, P.; et al. Biased ligand of the angiotensin II type 1 receptor in patients with acute heart failure: A randomized, double-blind, placebo-controlled, phase IIB, dose ranging trial (BLAST-AHF). Eur. Heart J. 2017, 38, 2364-2373. [CrossRef]

41. Hossain, A.; Heron, D.; Davenport, I.; Huckaba, T.; Graves, R.; Mandal, T.; Muniruzzaman, S.; Wang, S.; Bhattacharjee, P.S. Protective effects of bestatin in the retina of streptozotocin-induced diabetic mice. Exp. Eye Res. 2016, 149, 100-106. [CrossRef]

42. Dzoljić, E.; Varagić, V.M. Effects of bestatin and phosphoramidon on the hypertensive response to physostigmine in the rat. Fundam. Clin. Pharmacol. 1987, 1, 307-316. [CrossRef]

43. Tian, W.; Jiang, X.; Tamosiuniene, R.; Sung, Y.K.; Qian, J.; Dhillon, G.; Gera, L.; Farkas, L.; Rabinovitch, M.; Zamanian, R.T.; et al. Blocking macrophage leukotriene b4 prevents endothelial injury and reverses pulmonary hypertension. Sci. Transl. Med. 2013, 5, 200ra117. [CrossRef]

44. ClinicalTrials. A Study of Ubenimex in Patients with Pulmonary Arterial Hypertension (WHO Group 1) (LIBERTY). Available online: https://www.clinicaltrials.gov/ct2/show/study/NCT02664558?cond=Ubenimex\& rank=2 (accessed on 25 January 2019).

45. Qian, J.; Tian, W.; Jiang, X.; Tamosiuniene, R.; Sung, Y.K.; Shuffle, E.M.; Tu, A.B.; Valenzuela, A.; Jiang, S.; Zamanian, R.T.; et al. Leukotriene B4 Activates Pulmonary Artery Adventitial Fibroblasts in Pulmonary Hypertension. Hypertension 2015, 66, 1227-1239. [CrossRef] [PubMed]

46. ClinicalTrials. Open-Label Extension Study of Ubenimex in Patients with Pulmonary Arterial Hypertension (WHO Group 1) (LIBERTY2). Available online: https://www.clinicaltrials.gov/ct2/show/NCT02736149?cond= Ubenimex\&rank=3 (accessed on 25 January 2019).

47. ClinicalTrials. A Dose Finding Study to Assess the Effect of LIK066 Compared to Placebo or Empagliflozin in Patients With Type 2 Diabetes Mellitus and Heart Failure. Available online: https://www.clinicaltrials.gov/ ct2/show/record/NCT03152552?cond=LIK-066\&draw=2\&rank=10 (accessed on 25 January 2019).

48. Zuckerbraun, B.S.; Shiva, S.; Ifedigbo, E.; Mathier, M.A.; Mollen, K.P.; Rao, J.; Bauer, P.M.; Choi, J.J.; Curtis, E.; Choi, A.M.; et al. Nitrite potently inhibits hypoxic and inflammatory pulmonary arterial hypertension and smooth muscle proliferation via xanthine oxidoreductase-dependent nitric oxide generation. Circulation 2010, 121, 98-109. [CrossRef] [PubMed]

49. Hunter, C.J.; Dejam, A.; Blood, A.B.; Shields, H.; Kim-Shapiro, D.B.; Machado, R.F.; Tarekegn, S.; Mulla, N.; Hopper, A.O.; Schechter, A.N.; et al. Inhaled nebulized nitrite is a hypoxia-sensitive NO-dependent selective pulmonary vasodilator. Nat. Med. 2004, 10, 1122-1127. [CrossRef] [PubMed]

50. Rix, P.J.; Vick, A.; Attkins, N.J.; Barker, G.E.; Bott, A.W.; Alcorn, H., Jr.; Gladwin, M.T.; Shiva, S.; Bradley, S.; Hussaini, A.; et al. Pharmacokinetics, pharmacodynamics, safety, and tolerability of nebulized sodium nitrite (AIR001) following repeat-dose inhalation in healthy subjects. Clin. Pharmacokinet. 2015, 54, 261-272. [CrossRef] [PubMed]

51. ClinicalTrials. Dose-Finding, Safety, Pharmacodynamic Effect Study of Sodium Nitrite Inhalation Solution in Normal, Healthy Volunteers (AIR001-CS02). Available online: https://www.clinicaltrials.gov/ct2/show/ study/NCT00814645? cond=sodium+nitrite\&draw=5\&rank=15 (accessed on 15 February 2019).

52. ClinicalTrials. Safety, Tolerability, and PK Parameters of Sodium Nitrite Inhalation Solution in Healthy Subjects. Available online: https://www.clinicaltrials.gov/ct2/show/record/NCT01409122?cond=sodium+ nitrite\&draw $=4 \&$ rank=8\&view $=$ record (accessed on 15 February 2019).

53. ClinicalTrials. Pilot Study of Sodium Nitrite in Resuscitated Cardiac Arrest Patients. Available online: https://clinicaltrials.gov/ct2/show/NCT01178359 (accessed on 15 February 2019).

54. Dezfulian, C.; Olsufka, M.; Fly, D.; Scruggs, S.; Do, R.; Maynard, C.; Nichol, G.; Kim, F. Hemodynamic effects of IV sodium nitrite in hospitalized comatose survivors of out of hospital cardiac arrest. Resuscitation 2018, 122, 106-112. [CrossRef] [PubMed] 
55. UNITEDSTATES SECURITIES AND EXCHANGE COMMISSION. Form-10Q, 30 Sep 2014; p. 20. Available online: http://www.sec.gov/Archives/edgar/data/1160308/000156459014004815/mstx-10q_20140930.htm (accessed on 15 February 2019).

56. ClinicalTrials. A Phase 2 Study to Determine the Safety and Efficacy of AIR001 in Subjects with Pulmonary Arterial Hypertension (PAH). Available online: https:/www.clinicaltrials.gov/ct2/show/NCT01725256? cond= sodium +nitrite\&draw $=3 \&$ rank=24 (accessed on 15 February 2019).

57. ClinicalTrials. Long-Term Study of AIR001 in Subjects with WHO Group 1 Pulmonary Arterial Hypertension Who Completed AIR001-CS05. Available online: https://www.clinicaltrials.gov/ct2/show/ record/NCT01725269? cond=sodium+nitrite\&draw=6\&rank=23 (accessed on 15 February 2019).

58. ClinicalTrials. Inhaled Sodium Nitrite on Heart Failure with Preserved Ejection Fraction. Available online: https://www.clinicaltrials.gov/ct2/show/study/NCT02262078?cond=Sodium+Nitrite+on+ Heart+Failure\&rank=1 (accessed on 15 February 2019).

59. Borlaug, B.A.; Melenovsky, V.; Koepp, K.E. Inhaled Sodium Nitrite Improves Rest and Exercise Hemodynamics in Heart Failure With Preserved Ejection Fraction. Circ. Res. 2016, 119, 880-886. [CrossRef] [PubMed]

60. Borlaug, B.A.; Anstrom, K.J.; Lewis, G.D.; Shah, S.J.; Levine, J.A.; Koepp, G.A.; Givertz, M.M.; Felker, G.M.; LeWinter, M.M.; Mann, D.L.; et al. Effect of Inorganic Nitrite vs Placebo on Exercise Capacity Among Patients with Heart Failure with Preserved Ejection Fraction: The INDIE-HFpEF Randomized Clinical Trial. JAMA 2018, 320, 1764-1773. [CrossRef] [PubMed]

61. ClinicalTrials. Inorganic Nitrite Delivery to Improve Exercise Capacity in HFpEF (INDIE-HFpEF). Available online: https:/clinicaltrials.gov/ct2/show/NCT02742129 (accessed on 15 February 2019).

62. Savara Pharmaceuticals. Press Release. 11 March 2019. Available online: https://savarapharma.com/ investors/press-releases/release/?id=2337400 (accessed on 19 April 2019).

63. Takeda. Takeda FY2016 Q4 Results Data Book. Available online: https://www.takeda.com/siteassets/system/ investors/report/quarterlyannouncements/fy2016/fy-2016-q4-announcements-released-on-may-10-2017/ qr2016_q4_d1_en.pdf (accessed on 19 June 2019).

64. ClinicalTrials. A Phase I Food Effect Study of TAK-536TCH Final Formulation Tablet. Available online: https://www.clinicaltrials.gov/ct2/show/record/NCT02348658?term=TAK-536TCH\&rank=1 (accessed on 19 November 2018).

65. Rakugi, H.; Shimizu, K.; Sano, Y.; Nishiyama, Y.; Kinugawa, Y.; Terashio, S. Effects of triple combination therapy with azilsartan/amlodipine/hydrochlorothiazide on office/home blood pressure: A randomized-controlled trial in Japanese essential hypertensive patients. Blood Press. Monit. 2018, 23, 91-102. [CrossRef]

66. ClinicalTrials. Study to Evaluate the Efficacy and Safety of Combined Administration of TAK-536CCB and Hydrochlorothiazide in Patients with Grade I or II Essential Hypertension. Available online: https://www.clinicaltrials.gov/ct2/show/NCT02072330?term=Takeda\&cond=Essential+ Hypertension\&rank=5 (accessed on 19 April 2018).

67. Rakugi, H.; Shimizu, K.; Nishiyama, Y.; Sano, Y.; Umeda, Y. A phase III, open-label, multicenter study to evaluate the safety and efficacy of long-term triple combination therapy with azilsartan, amlodipine, and hydrochlorothiazide in patients with essential hypertension. Blood Press. 2018, 27, 125-133. [CrossRef]

68. ClinicalTrials. A Phase III Long-term Study of TAK-536TCH in Participants with Essential Hypertension. Available online: https://www.clinicaltrials.gov/ct2/show/NCT02277691?term=Takeda\&cond=Essential+ Hypertension\&rank=1 (accessed on 19 April 2018).

69. Kragholm, K.; Newby, L.K.; Melloni, C. Emerging treatment options to improve cardiovascular outcomes in patients with acute coronary syndrome: Focus on losmapimod. Drug Des. Dev. Ther. 2015, 9, 4279-4286.

70. Willette, R.N.; Eybye, M.E.; Olzinski, A.R.; Behm, D.J.; Aiyar, N.; Maniscalco, K.; Bentley, R.G.; Coatney, R.W.; Zhao, S.; Westfall, T.D.; et al. Differential effects of p38 mitogen-activated protein kinase and cyclooxygenase 2 inhibitors in a model of cardiovascular disease. J. Pharmacol. Exp. Ther. 2009, 330, 964-970. [CrossRef] [PubMed]

71. Zhang, X.M.; Zhang, L.; Wang, G.; Niu, W.; He, Z.; Ding, L.; Jia, J. Suppression of mitochondrial fission in experimental cerebral ischemia: The potential neuroprotective target of p38 MAPK inhibition. Neurochem. Int. 2015, 90, 1-8. [CrossRef] [PubMed] 
72. Ino, H.; Takahashi, N.; Terao, T.; Igarashi, H.; Sarai, N. Safety, tolerability, pharmacokinetics, and pharmacodynamics of losmapimod in healthy Japanese volunteers. Clin. Pharmacol. Drug Dev. 2015, 4, 262-269. [CrossRef] [PubMed]

73. ClinicalTrials. Phase I Study of GW856553 (Losmapimod). Available online: https://www.clinicaltrials.gov/ ct2/show/study/NCT01648192?term=Losmapimod\&rank=6 (accessed on 28 December 2018).

74. Barbour, A.M.; Sarov-Blat, L.; Cai, G.; Fossler, M.J.; Sprecher, D.L.; Graggaber, J.; McGeoch, A.T.; Maison, J.; Cheriyan, J. Safety, tolerability, pharmacokinetics and pharmacodynamics of losmapimod following a single intravenous or oral dose in healthy volunteers. Br. J. Clin. Pharmacol. 2013, 76, 99-106. [CrossRef] [PubMed]

75. ClinicalTrials. PK Study of IV Formulation of GW856553. Available online: https://www.clinicaltrials.gov/ ct2/show/record/NCT01039961?term=Losmapimod\&rank=8 (accessed on 28 December 2018).

76. Yang, S.; Beerahee, M. Losmapimod concentration-QT relationship in healthy volunteers: Meta-analysis of data from six clinical trials. Eur. J. Clin. Pharmacol. 2013, 69, 1261-1267. [CrossRef] [PubMed]

77. Newby, L.K.; Marber, M.S.; Melloni, C.; Sarov-Blat, L.; Aberle, L.H.; Aylward, P.E.; Cai, G.; de Winter, R.J.; Hamm, C.W.; Heitner, J.F.; et al. Losmapimod, a novel p38 mitogen-activated protein kinase inhibitor, in non-ST-segment elevation myocardial infarction: A randomised phase 2 trial. Lancet 2014, 384, 1187-1195. [CrossRef]

78. Melloni, C.; Sprecher, D.L.; Sarov-Blat, L.; Patel, M.R.; Heitner, J.F.; Hamm, C.W.; Aylward, P.; Tanguay, J.F.; DeWinter, R.J.; Marber, M.S.; et al. The study of LoSmapimod treatment on inflammation and InfarCtSizE (SOLSTICE): Design and rationale. Am. Heart J. 2012, 164, 646-653. [CrossRef]

79. Aronow, W.S.; Kaple, R.K. Losmapimod does not reduce cardiovascular events in patients with acute myocardial infarction. J. Thorac. Dis. 2016, 8, 2328-2330. [CrossRef]

80. O’Donoghue, M.L.; Glaser, R.; Cavender, M.A.; Aylward, P.E.; Bonaca, M.P.; Budaj, A.; Davies, R.Y.; Dellborg, M.; Fox, K.A.; Gutierrez, J.A.; et al. Effect of Losmapimod on Cardiovascular Outcomes in Patients Hospitalized With Acute Myocardial Infarction: A Randomized Clinical Trial. JAMA 2016, 315, 1591-1599. [CrossRef]

81. O'Donoghue, M.L.; Glaser, R.; Aylward, P.E.; Cavender, M.A.; Crisp, A.; Fox, K.A.; Laws, I.; Lopez-Sendon, J.L.; Steg, P.G.; Theroux, P.; et al. Rationale and design of the LosmApimod To Inhibit p38 MAP kinase as a TherapeUtic target and moDify outcomes after an acute coronary syndromE trial. Am. Heart J. 2015, 169, 622-630. [CrossRef]

82. ClinicalTrials. A Phase 3 Clinical Outcomes Study to Compare the Incidence of Major Adverse Cardiovascular Events in Subjects Presenting With Acute Coronary Syndrome Treated with Losmapimod Compared to Placebo (LATITUDE-TIMI 60) (LATITUDE). Available online: https:/clinicaltrials.gov/ct2/show/ NCT02145468?term=GlaxoSmithKline++Losmapimod\&cond=Myocardial + Infarction\&rank=1 (accessed on 23 April 2018).

83. Udata, C.; Garzone, P.D.; Gumbiner, B.; Joh, T.; Liang, H.; Liao, K.H.; Williams, J.H.; Meng, X. A MechanismBased Pharmacokinetic/Pharmacodynamic Model for Bococizumab, a Humanized Monoclonal Antibody Against Proprotein Convertase Subtilisin/Kexin Type9, and Its Application in Early Clinical Development. J. Clin. Pharmacol. 2017, 57, 855-864. [CrossRef] [PubMed]

84. Hadjiphilippou, S.; Ray, K.K. PCSK9 inhibition and atherosclerotic cardiovascular disease prevention: Does reality match the hype? Heart 2017, 103, 1670-1679. [CrossRef] [PubMed]

85. ClinicalTrials. A Study to Access the Safety And Tolerability of RN316 (PF-04950615) When Administered to Healthy Adult Subjects. Available online: https://www.clinicaltrials.gov/ct2/show/record/NCT00991159? term=NCT00991159\&rank=1 (accessed on 28 December 2018).

86. ClinicalTrials. A Pharmacokinetic and Pharmacodynamic Study of PF-04950615 in Subjects with Hypercholesterolemia. Available online: https://www.clinicaltrials.gov/ct2/show/record/NCT01435382? term=NCT01435382\&rank=1 (accessed on 28 December 2018).

87. ClinicalTrials. Safety and Tolerability of Multiple Doses of PF-04950615 (RN316) in Subjects with Hypercholesterolemia. Available online: https://www.clinicaltrials.gov/ct2/show/record/NCT01243151? term $=$ NCT01243151\&rank=1 (accessed on 28 December 2018).

88. Wan, H.; Gumbiner, B.; Joh, T.; Riel, T.; Udata, C.; Forgues, P.; Garzone, P.D. Effects of Proprotein Convertase Subtilisin/Kexin Type 9 (PCSK9) Inhibition with Bococizumab on Lipoprotein Particles in Hypercholesterolemic Subjects. Clin. Ther. 2017, 39, 2243-2259. [CrossRef] [PubMed] 
89. Ballantyne, C.M.; Neutel, J.; Cropp, A.; Duggan, W.; Wang, E.Q.; Plowchalk, D.; Sweeney, K.; Kaila, N.; Vincent, J.; Bays, H. Results of bococizumab, a monoclonal antibody against proprotein convertase subtilisin/kexin type 9, from a randomized, placebo-controlled, dose-ranging study in statin-treated subjects with hypercholesterolemia. Am. J. Cardiol. 2015, 115, 1212-1221. [CrossRef] [PubMed]

90. Chaparro-Riggers, J.; Liang, H.; DeVay, R.M.; Bai, L.F.; Sutton, J.E.; Chen, W.; Geng, T.; Lindquist, K.; Casas, M.G.; Boustany, L.M.; et al. Increasing serum half-life and extending cholesterol lowering in vivo by engineering antibody with pH-sensitive binding to PCS-K9. J. Biol. Chem. 2012, 287, 11090-11097. [CrossRef]

91. Pfizer. Pfizer Discontinues Global Development of Bococizumab, Its Investigational PCSK9 Inhibitor. Available online: https:/www.pfizer.com/news/press-release/press-releasedetail/pfizer_discontinues_global_ development_of_bococizumab_its_investigational_pcsk9_inhibitor (accessed on 24 November 2018).

92. ClinicalTrials. Pharmacokinetic and Pharmacodynamic Study of Bococizumab Alone and When Combined with Recombinant Human Hyaluronidase. Available online: https://clinicaltrials.gov/ ct2/show/NCT02667223?term=Pfizer+Bococizumab\&cond=Hypercholesterolaemia\&rank=2 (accessed on 24 November 2018).

93. Ridker, P.M.; Tardif, J.C.; Amarenco, P.; Duggan, W.; Glynn, R.J.; Jukema, J.W.; Kastelein, J.J.P.; Kim, A.M.; Koenig, W.; Nissen, S.; et al. Lipid-Reduction Variability and Antidrug-Antibody Formation with Bococizumab. N. Engl. J. Med. 2017, 376, 1517-1526. [CrossRef]

94. Ridker, P.M.; Rose, L.M.; Kastelein, J.J.P.; Santos, R.D.; Wei, C.; Revkin, J.; Yunis, C.; Tardif, J.C.; Shear, C.L. Cardiovascular event reduction with PCSK9 inhibition among 1578 patients with familial hypercholesterolemia: Results from the SPIRE randomized trials of bococizumab. J. Clin. Lipidol. 2018, 12, 958-965. [CrossRef] [PubMed]

95. ClinicalTrials. A 52 Week Study to Assess the Use of Bococizumab (PF-04950615; RN316) in Subjects with Heterozygous Familial Hypercholesterolemia (SPIRE-FH). Available online: https:/clinicaltrials.gov/ct2/ show/NCT01968980?term=Pfizer+Bococizumab\&rank=8 (accessed on 24 November 2018).

96. Ridker, P.M.; Revkin, J.; Amarenco, P.; Brunell, R.; Curto, M.; Civeira, F.; Flather, M.; Glynn, R.J.; Gregoire, J.; Jukema, J.W.; et al. Cardiovascular Efficacy and Safety of Bococizumab in High-Risk Patients. N. Engl. J. Med. 2017, 376, 1527-1539. [CrossRef]

97. ClinicalTrials. The Evaluation of Bococizumab (PF-04950615; RN316) in Reducing the Occurrence of Major Cardiovascular Events in High Risk Subjects. Available online: https://www.clinicaltrials.gov/ct2/show/ record/NCT01975389?term=NCT01975389\&rank=1 (accessed on 29 June 2019).

98. FDA. FDA Approves Praluent to Treat Certain Patients with High Cholesterol. Available online: https: //www.fda.gov/newsevents/newsroom/pressannouncements/ucm455883.htm (accessed on 23 April 2018).

99. Amgen. FDA Approves Amgen's Repatha (evolocumab) To Prevent Heart Attack and Stroke. Available online: http://www.amgen.com/media/news-releases/2017/12/fda-approves-amgens-repathaevolocumab-to-prevent-heart-attack-and-stroke/ (accessed on 24 January 2019).

100. Kola, I.; Landis, J. Can the pharmaceutical industry reduce attrition rates? Nat. Rev. Drug Discov. 2004, 3, 711-715. [CrossRef]

101. BIO, Biomedtracker, Amplion. Clinical Development Success Rates 2006-2015. 25 May 2016. Available online: https:/www.bio.org/sites/default/files/Clinical\%20Development\%20Success\%20Rates\% 202006-2015\%20-\%20BIO,\%20Biomedtracker,\%20Amplion\%202016.pdf (accessed on 18 March 2019).

(C) 2019 by the authors. Licensee MDPI, Basel, Switzerland. This article is an open access article distributed under the terms and conditions of the Creative Commons Attribution (CC BY) license (http://creativecommons.org/licenses/by/4.0/). 